\title{
Agenesia de artéria pulmonar
}

\author{
Agenesis of pulmonary artery
}

Marcel Koenigkam Santos ${ }^{1}$

Neste volume da revista Medicina (Ribeirão Preto) os leitores vão encontrar dois artigos interessantes de Queiroz et al. (2020) e Silva et al. (2020) sobre a agenesia de artéria pulmonar direita. Nestes artigos, os autores descrevem casos de pacientes com agenesia de artéria pulmonar direita muito bem documentados com exames de imagem ${ }^{1,2}$. Como descrito pelos autores, apesar de se tratar de uma entidade muito rara, o aspecto de imagem observado principalmente no exame de angiotomografia computadorizada (angioTC) é bastante característico.

A agenesia (ausência) isolada de artéria pulmonar direita ou esquerda é entidade congênita rara afetando menos de $0,3 \%$ da população. Quando à esquerda, usualmente é sintomática e relacionada a outras malformações cardíacas. Já a agenesia à direita pode ser assintomática e representar achado de exame de imagem ${ }^{3,4}$.

As alterações radiográficas podem variar dependendo do lado afetado. Mais tipicamente observa-se, na radiografia simples (RX), assimetria de volume e transparência dos hemitóraces, com redução de volume e aumento da transparência do pulmão acometido, como descrito pelos autores ${ }^{1.2}$. Este padrão de RX faz diagnóstico diferencial principalmente com alterações pós cirúrgicas (lobectomia, pneumectomia), síndrome do pulmão hipogenético (síndrome da cimitarra), síndrome de Swyer-James-Macloud e o enfisema (hiperinsuflação) lobar congênito $5,6,7$.

Na síndrome da cimitarra, também uma malformação congênita, observa-se o pulmão afetado de volume reduzido, com desvio ipsilateral do mediastino, associado a imagem tubular vertical paralela à margem cardíaca direita representando o retorno venoso parcial anômalo, lembrando a imagem da espada turca tipo cimitarra5.

A síndrome de Swyer-James-Macloud representa complicação de bronquiolite obliterante pós infecciosa grave na infância. A imagem radiográfica mostra o pulmão afetado de volume reduzido, hipertransparente, apresentado retenção aérea importante se for realizado o exame em expiração. O hilo pulmonar ipsilateral tem volume reduzido 6 .

O enfisema lobar congênito, outra malformação congênita, resulta em hiperinsuflação progressiva de um ou mais lobos pulmonares no neonato, mais comum no sexo masculino. Pode estar associado a malformações cardiovasculares. Na imagem radiográfica, observa-se o pulmão afetado com aspecto hipertransparente e de volume aumentado, levando ao desvio contralateral do mediastino?.

Desta maneira, o diagnóstico de agenesia isolada de artéria pulmonar direita na imagem de RX é difícil e inclui alguns diagnósticos diferenciais que devem ser lembrados. Os artigos publicados nesta edição da Revista Medicina trazem boa descrição dos achados clínicos e das imagens de angioTC, ressaltando o papel deste exame de imagem na avaliação desta entidade.

1. Docente colaborador da Fundação de Apoio ao Ensino, Pesquisa e Assistência do Hospital das Clínicas da Faculdade de Medicina de Ribeirão Preto da Universidade de São Paulo (FAEPA), Ribeirão Preto (SP), Brasil.

$\triangle$ Avenida Bandeirantes, 3900 - Campus Universitário. CEP: 14049-900. Ribeirão Preto (SP), Brasil. marcelk46@fmrp.usp.br 


\section{REFERÊNCIAS}

1. Queiroz RM, Tannus CS, Boyadjian AA, Beneduzzi ML, Mello DFRE, Febronio EM, et al. Agenesia da artéria pulmonar direita: descrição de caso. Medicina (Ribeirão Preto). 2020;53(1):55-59. Doi: https://doi.org/10.11606/issn.2176-7262. v53i1p55-59.

2. Silva ISD, Magalhães EF, Pereira LCM, Braga LCC, Femía VZ, Serrano CBA, et al. Agenesia de artéria pulmonar direita: relato de caso. Medicina (Ribeirão Preto). 2020;53(1):61-65. Doi: https://doi.org/10.11606/issn.2176-7262.v53i1p61-65.

3. Ten Harkel AD, Blom NA, Ottenkamp J. Isolated unilateral absence of a pulmonary artery: a case report and review of the literature. Chest. 2002;122 (4):1471-7.

4. Kruzliak P, Syamasundar RP, Novak M et-al. Unilateral absence of pulmonary artery: pathophysiology, symptoms, diagnosis and current treatment. Arch Cardiovasc Dis. 2013;106(8-9):448-54.

5. Vida VL, Padalino MA, Boccuzzo G et-al. Scimitar syndrome: a European Congenital Heart Surgeons Association (ECHSA) multicentric study. Circulation. 2010;122(12):1159-66.

6. Zylak CJ, Eyler WR, Spizarny DL et-al. Developmental lung anomalies in the adult: radiologic-pathologic correlation. Radiographics. 2002;22:S25-43.

7. Stigers $\mathrm{KB}$, Woodring $\mathrm{JH}$, Kanga JF. The clinical and imaging spectrum of findings in patients with congenital lobar emphysema. Pediatr. Pulmonol. 1992;14(3):160-70. 